\section{Commentary: Hospital-acquired infections after cardiac surgery: More dangerous than we may have believed}

\author{
Eric W. Etchill, MD, MPH, and \\ Glenn J. R. Whitman, MD
}

Massert and colleagues ${ }^{1}$ examine the incremental mortality risk attributed to 3 specific hospital-acquired infections (HAIs) after cardiac surgery: thoracic surgical site (not vein harvest), blood stream infections, and pneumonia. The authors performed a retrospective review of prospectively collected data in 8853 patients who underwent cardiac surgery at a single institution between 2012 and 2018 and found that roughly $4 \%$ of all patients developed postoperative HAI. By Cox regression, HAI was independently associated with hospital mortality, with a hazard ratio of more than 4 in both valve and coronary surgery $(P<.001)$. In an effort to avoid confounding and provide additional support for their findings, from 740 patients propensity matched (370 in each group) with and without HAI, matched on every variable (close to 30 ) independently associated with HAI or death, the authors determined an attributable mortality of $17 \%$ to be associated with HAI. Finally, using logistic regression they determined that pseudomonal infections, bloodstream infections, and pneumonia were each independently associated with an approximate 4-fold increase in 90-day mortality.

As one might have guessed, when patients with HAI were compared with the entire population (HAI and non-HAI patients altogether), those who developed HAI were more morbid, with a European System for Cardiac Operative Risk Evaluation II score of 4.3 versus 2.4, were more likely to undergo emergent surgery, had longer bypass times, and

\footnotetext{
From the Division of Cardiothoracic Surgery, Department of Surgery, University of Maryland School of Medicine, Baltimore, Md.

Disclosures: The authors reported no conflicts of interest.

The Journal policy requires editors and reviewers to disclose conflicts of interest and to decline handling or reviewing manuscripts for which they may have a conflict of interest. The editors and reviewers of this article have no conflicts of interest.

Received for publication Sept 18, 2020; revisions received Sept 18, 2020; accepted for publication Sept 18, 2020; available ahead of print Sept 29, 2020.

Address for reprints: Glenn J. R. Whitman, MD, Division of Cardiovascular Surgery, Department of Surgery, Johns Hopkins Hospital, 1800 Orleans St, Sheikh Zayed Tower Suite 7107, Baltimore, MD 21287 (E-mail: gwhitman@jhmi.edu).

J Thorac Cardiovasc Surg 2022;163:2143-4

$0022-5223 / \$ 36.00$

Copyright (c) 2020 by The American Association for Thoracic Surgery

https://doi.org/10.1016/j.jtcvs.2020.09.082
}

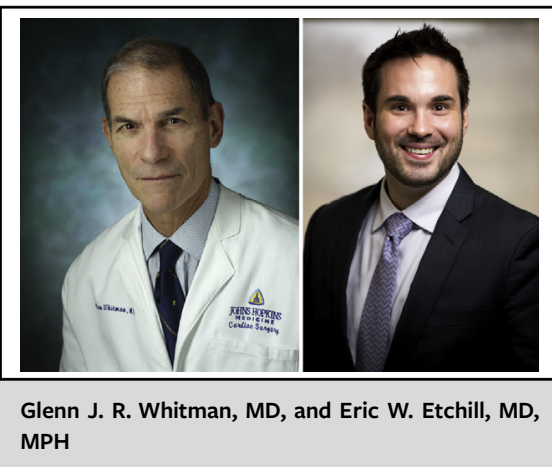

CENTRAL MESSAGE

Hospital-acquired infections, although thankfully uncommon, drastically increase morbidity and mortality in the vulnerable population.

received more transfusions. Not surprisingly, they had longer lengths of stay (median 24 vs 10 days) and higher in-hospital (15.4\% vs $2.9 \%)$ and 90 -day mortality $(20 \%$ vs $2.9 \%$ ). Logistic regression accomplished the task of determining the hazard ratio of death associated with HAI in these patients.

The takeaway lesson from the propensity-matched study is somewhat enigmatic. In the HAI group, there were 57 deaths versus 21 deaths in the matched population, yielding $15.4 \%$ versus $5.6 \%$ mortality, respectively. We believe the mortality attributable to HAI should be determined in this matched population, rather than comparing the mortality associated with HAI to the entire cohort of 8800 patients who had far fewer comorbidities as a group, invalidating the comparison. Done this way, the excess hospital and 90-day mortality of 36 and 46 deaths, respectively, should be divided by the total mortality in the 740 matched patients, not the entire cohort of 8853 patients, yielding an excess mortality of 36 out of 78 for in-hospital mortality and 46 out of 102 for 90 day mortality, both being approximately $45 \%$, not $17 \%$. To us, the data suggest that postoperative HAI confers far more mortality and morbidity than was concluded by these authors.

The major limitation of this article is inadequate determination of the time-dependent nature of the diagnosis of HAI. It is more than possible that the HAI seen may have been the sequela of other attributable causes of death rather than their cause. Although we do not have information on other factors that are known to be associated with infection and 
thus were not controlled for; for example, malnutrition, prolonged immobility, lengthy intensive care unit stay, and blood sugar control, the message is clear. HAI after cardiac surgery, despite being infrequent, is associated with significant morbidity and mortality. By defining those patients most susceptible to HAI and having quantified the toll that HAI exacts, the authors' message emphasizes the importance of avoiding the controllable variables that lead to HAI, determined by this study and others, including preoperative smoking cessation, transfusions, prolonged bypass times, prolonged ventilation times, and postoperative kidney injury. ${ }^{2,3}$ Although exactly how much of an increased risk it poses may not have been answered, the overarching, significantly deleterious effect of HAI should be undisputed.

\section{References}

1. Massert N, Mansour A, Ross J, Piau C, Verhoye J-P, Tattevin P, et al. Mortality due to hospital-acquired infection after cardiac surgery. J Thorac Cardiovasc Surg. 2022;163:2131-40.e3.

2. Horvath KA, Acker MA, Chang H, Bagiella E, Smith PK, Iribarne A, et al. Blood transfusion and infection after cardiac surgery. Ann Thorac Surg. 2013;95: 2194-201.

3. Ginwalla R, Faraday N, Whitman G. Postoperative management of the cardiac surgical patient. In: Yuh DD, Vricella LA, Yang SC, Doty JR, eds. Johns Hopkins Textbook of Cardiothoracic Surgery. New York, NY: McGraw-Hill Education; 2014. 